\title{
Optimized Preparation of Polyacrylonitrile/Sulfur Composite as Cathode for Lithium Sulfur Batteries
}

\author{
Jiaxin Pan ${ }^{1,2}$, Jia Nie $^{1}$,Bing Zeng ${ }^{3}$, Xianbiao Chen $^{3}$, Zhe Chen $^{3}$, Dongqi Kang ${ }^{3}$, Yinbao Miao ${ }^{3}$, \\ Weihao Liu', Wenhua Zhang ${ }^{3, *}$ \\ ${ }^{1}$ College of Chemistry \& Molecule Science, Wuhan University, Bayi road No.299, Wuhan 430072, \\ China \\ ${ }^{2}$ Guangxi Institute of science and technology information, Xinghu road No.24, Nanning 530022, \\ China \\ ${ }^{3}$ Nanchang Institute of Technology, Tianxiang Avenue No.289, Nanchang 330099, China \\ *E-mail: 2015994552@ nit.edu.cn
}

Received: 20 September 2021 / Accepted: 22 October 2021 / Published: 5 January 2022

The polyacrylonitrile/sulfur (PAN/S)composite was prepared by heating the mixture of polyacrylonitrile (PAN) and sulfur under sealed conditions. The effects of the ratio of raw materials, reaction temperature, reaction time and reaction container volume on the properties of the composite product were studied to optimize the preparation conditions of the PAN/S composite. The results showed that the PAN/S composite with the mass ratio of 1:1.5 had the best properties, which was prepared in a large container in a high temperature reaction kettle at $300^{\circ} \mathrm{C}-400^{\circ} \mathrm{C}$ for 12 hours. Based on the total mass of the composite, the initial discharge capacity of the composite is $856 \mathrm{mAh} \mathrm{g}^{-1}$ and the reversible specific capacity is $678 \mathrm{mAh} \mathrm{g}^{-1}$. After 100 cycles, the specific capacity of the composite is stable at $584 \mathrm{mAh} \mathrm{g}^{-}$ 1 , and the capacity retention rate is $86.1 \%$, showing a good application prospect.

Keywords: Li-S battery, sulfur cathode, PAN/S composites

\section{$\underline{\text { FULL TEXT }}$}

(C) 2022 The Authors. Published by ESG (www.electrochemsci.org). This article is an open access article distributed under the terms and conditions of the Creative Commons Attribution license (http://creativecommons.org/licenses/by/4.0/). 